\title{
Anovulatory and ovulatory infertility: results with simplified management
}

\author{
M G R HULL，P E SAVAGE，D R BROMHAM
}

\begin{abstract}
A simplified scheme for the management of anovulatory and of ovulatory (usually called unexplained) infertility was evaluated in 244 women. Eighteen patients were excluded because of primary ovarian failure, 164 were treated for ovulatory failure, and 62 with ovulatory infertility remained untreated. Twenty-five patients had a properly validated negative postcoital test. In the remaining 201 patients the two-year conception rates were $96 \%$ in patients with amenorrhoea, $83 \%$ in those with oligomenorrhoea, $74 \%$ in those with luteal deficiency, and $88 \%$ in those with ovulatory infertility.

Comparison with normal rates implied that amenorrhoea represents a pure form of ovulatory failure that is completely correctable whereas in other conditions unexplained factors also contribute to infertility though to a much smaller extent than was previously thought.
\end{abstract}

\section{Introduction}

The aim of this paper is to show that the management of both anovulatory and "ovulatory" or unexplained infertility could be improved by a simple scheme using only the few tests of defined critical importance and uncomplicated treatment regimens. Some of the methods have been validated by our own studies and others are based on interpretation of the published reports reviewed in detail by Hull. ${ }^{1}$

University of Bristol Department of Obstetrics and Gynaecology, Bristol Maternity Hospital, Bristol BS2 8EG

M G R HULL, FRCOG, consultant senior lecturer

P E SAVAGE, FRCS, MRCOG, lecturer (now consultant senior lecturer)

D R BROMHAM, PHD, MRCOG, lecturer (now senior lecturer, Department of Obstetrics and Gynaecology, St James's Hospital, Leeds)
We have already shown that normal fertility can be restored in patients with amenorrhoea, ${ }^{2}$ and our simplified scheme has since been extended to patients with oligomenorrhoea and with luteal deficiency (women with a normal menstrual cycle but a deficient luteal progesterone concentration). We also give our results in patients with a completely normal cycle, who therefore received no treatment but in whom confidence not to treat depended on establishing the critical luteal progesterone level for fertility ("ovulation"). ${ }^{3}$

The results are presented as cumulative rates of conception and delivery of a baby. This allows comparison with rates of fecundity in a normal population. It also emphasises that the chance of conception depends on time and that, given confidence in the diagnostic methods, treatment may be continued without change or embellishment.

\section{Patients and methods}

All patients had at least 12 months' infertility; those with absolute pelvic or seminal causes were excluded. Amenorrhoea was defined as lasting at least six months in the absence of pregnancy and oligomenorrhoea as menstrual intervals greater than six weeks and less than six months. We made no attempt to detect whether ovulation occurred in such prolonged cycles.

The scheme of management is shown in fig 1. Patients with a normal menstrual cycle (3-6 weeks) had a single measurement of the serum progesterone concentration timed to occur 5-10 days before the ensuing menstrual period in two or three cycles. The patients were classed as ovulatory if the progesterone value was at least $30 \mathrm{nmol} / 1$ $(9 \cdot 4 \mathrm{ng} / \mathrm{ml})^{3}$ in two of the three cycles. Conversely, those with a value less than $30 \mathrm{nmol} / 1$ in two cycles were classed as having luteal deficiency, which for practical purposes was taken to be a form of ovulatory failure. ${ }^{34} \mathrm{~A}$ semen analysis was done in all cases.

Patients with a normal menstrual cycle (or with ovulation induced by treatment) kept a basal body temperature chart to time the occurrence of ovulation, if possible. Endometrial biopsy was never used. Once ovulation was established a postcoital test was performed, and later if necessary laparoscopy. 
Patients with ovulatory failure had a careful history taken with emphasis on psychological factors and previous weight loss, particularly in oligomenorrhoea or amenorrhoea; the use of prolactinergic drugs; symptoms of thyroid disorder; and hirsutism. Along with a general and pelvic examination the height and weight were measured and the urine tested for glucose. The only other routine tests were measurement of serum activities of follicle-stimulating hormone (FSH) and prolactin and determination of the free thyroxine index (repeated for confirmation if the value was abnormal).

The response to clomiphene was tested in terms of ovulation using the criterion for progesterone given above. Clomiphene 50-100 mg was given for five days from the second day of menstruation or initially in oligomenorrhoeic or amenorrhoeic patients one week after a challenge with oral medroxyprogesterone acetate ( $5 \mathrm{mg}$ for five days) to determine the oestrogen state. ${ }^{5}$ The lower dose of clomiphene was used at first in oestrogenised patients and the higher dose if they failed to ovulate, whereas the higher dose was selected immediately in all oligomenorrhoeic or amenorrhoeic patients who after the progestogen challenge failed to menstruate or who bled only scantily (decided by the patient).

Oestrogenised patients were treated with clomiphene for at least three cycles if necessary but without increasing the daily dose above $100 \mathrm{mg}$ or any other modification. If only impaired responses occurred (menstruation but luteal deficiency) human chorionic gonadotrophin 10000 IU on day 13 of the cycle was later added. The same applied to the few oestrogen-deficient patients who responded at all to clomiphene, otherwise treatment proceeded immediately to bromocriptine or gonadotrophins. Bromocriptine was used in a standard dose of 7.5 $\mathrm{mg} /$ day, increased only if the prolactin activity was not suppressed to normal and continued until pregnancy was diagnosed. Human menopausal gonadotrophin was given in daily doses determined by 24 -hour urinary oestrogen excretion and by no other form of monitoring; ovulation was induced with human chorionic gonadotrophin (10 000 IU as a single dose) when oestrogen excretion had risen to $250-400$ $\mathrm{nmol} /$ day (about 70-115 $\mu \mathrm{g} /$ day).

Patients with postmenopausal FSH levels were diagnosed as having primary ovarian failure and were not treated to induce ovulation. Patients whose treatment with clomiphene or bromocriptine selected as in fig 1 failed to induce ovulation were treated with gonadotrophins (unless the polycystic ovary syndrome was suspected: see below) Once ovulation was established as defined above it was not checked in most subsequent cycles, and treatment was continued without modification as long as needed to achieve conception provided other factors seemed favourable. In particular, the dose of clomiphene was not increased above $100 \mathrm{mg} /$ day and supplementation in mid-cycle with oestrogen or in the luteal phase with progesterone or human chorionic gonadotrophin was never used.

Special management was conducted as appropriate to discover a possibly dangerous tumour in the pituitary region in cases of hyperprolactinaemia ${ }^{6}$ or to confirm thyroid disorder when the free thyroxine index was abnormal. 7 Hirsutism suggesting a hyperandrogen state was assumed to indicate polycystic ovaries and was not investigated further ${ }^{8}$ unless ovulation failed to occur in response to clomiphene (after repeated testing since the patients were usually oestrogenised), in which case treatment with corticosteroids was the first alternative. We have found no critical need for any dynamic tests other than the progestogen challenge and clomiphene tests as described above or for visualisation or biopsy of the ovaries. A few patients needed primary treatment for a large prolactinoma or thyroid disorder, or for amenorrhoea related to weight loss. ${ }^{910}$ These last were encouraged to increase their weight rather than receive gonadotrophin treatment.

The rates of conception and of ultimate childbirth after treatment were calculated as for life-table analysis, ${ }^{11}$ which allows for some patients not continuing as long as others in the study, and were compared with the highest normal rates similarly calculated ${ }^{11-13}$ and modified $^{13}$ for reference as discussed elsewhere. ${ }^{14}$ Results were timed from the start of definitive therapy, selected as in fig 1 or specifically for weight loss or thyroid disorder, without correcting for changes in treatment. Ablation of a pituitary tumour was considered to be a preliminary safety procedure before definitive treatment with bromocriptine.

A postcoital test was performed after ovulation was established, to ensure fully developed cervical mucus, using prospectively validated criteria. ${ }^{15}$ Since a negative response to a postcoital test performed in this way represents a distinct although not absolute cause of infertility ${ }^{15}$ the results have been presented before and after excluding patients with a negative response to the test.

\section{Results}

A consecutive series of 244 patients was studied, nearly half of them referred by other specialists, after those with absolute pelvic or seminal causes of infertility had been excluded. The commonest reasons for exclusion were bilateral tubal or peritubal occlusion and azoospermia or severe oligospermia (less than $5 \times 10^{6}$ spermatozoa $/ \mathrm{ml}$ semen, in all cases associated with a negative postcoital test result). Twenty-four patients were included with infertility factors of doubtful significance: unilateral tubal disease, mild endometriosis, infrequent coitus, or, most commonly, oligospermia of moderate degree $\left(5-19 \times 10^{6}\right.$ sper-

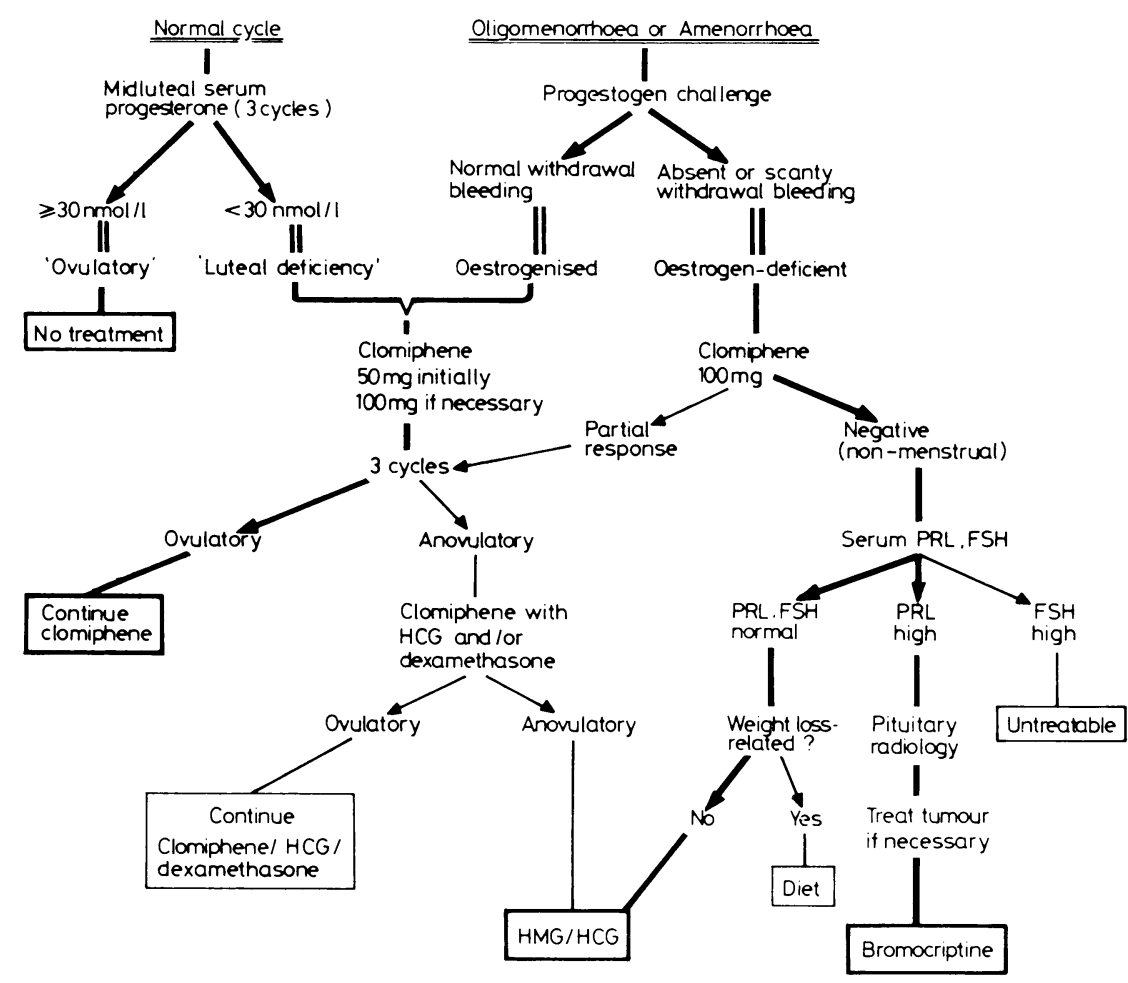

FIG 1-Flow-chart summary of management of anovulatory and ovulatory infertility, excluding investigations of unrelated causes of infertility. The common pathways to select treatment are shown by heavy lines and boxes. The chart does not include specific consideration of hyperandrogenism (although selection of treatment follows pathways shown) or of thyroid disorder.

$\mathrm{HMG}=$ Human menopausal gonadotrophin. $\mathrm{HCG}=$ Human chorionic gonadotrophin. FSH $=$ Follicle stimulating hormone (high, $>40 \mathrm{IU} / 1, \mathrm{MRC} 68 / 39$ ). PRL $=$ Prolactin (high, $>700 \mathrm{mU} / \mathrm{l}, 1$ st IRP) 
matozoa $/ \mathrm{ml}$ ). There were 182 patients with ovulatory failure, in whom the distribution of diagnoses is shown in fig 2, and 62 apparently normal patients with so-called ovulatory infertility. After excluding 18 patients with primary ovarian failure there remained 164 patients who needed treatment to induce ovulation and the 62 with ovulatory infertility who received no treatment. Their age and duration of infertility are given in table I. The overall age range was 19-42 years, and the duration of infertility was 1-9 years (median 2 years) - longer in some patients with amenorrhoea, which had lasted up to 25 years.

The distribution of treatments to induce ovulation is shown in fig 3. There was an apparent excess amounting to 5.5\% overall, representing nine patients who needed human menopausal gonadotrophin (8) or dexamethasone (1) when their origindlly selectuu iridtment had failed. Another nine patients $(5.5 \%)$ continued their original treatment only with modification: seven treated with clomiphene also received human chorionic gonadotrophin (7), dexamethasone (1), and/or ovarian wedge excision (1); and two dieted patients needed clomiphene because of luteal deficiency after menstruation had been restored.

The crude results were as follows. All treated patients ovulated. Of the 226 patients studied with or without treatment, $178(79 \%)$ have so far conceived, and $159(70 \%)$ have delivered and another two $(1 \%)$ are in advanced pregnancy. Only one patient who has delivered does not have a healthy surviving child. The multiple pregnancy rate was $8 \%(14 / 178)$, mainly associated with gonadotrophin treatment $(30 \%)$ and clomiphene $(6 \%)$. Six pregnancies were terminated, in-

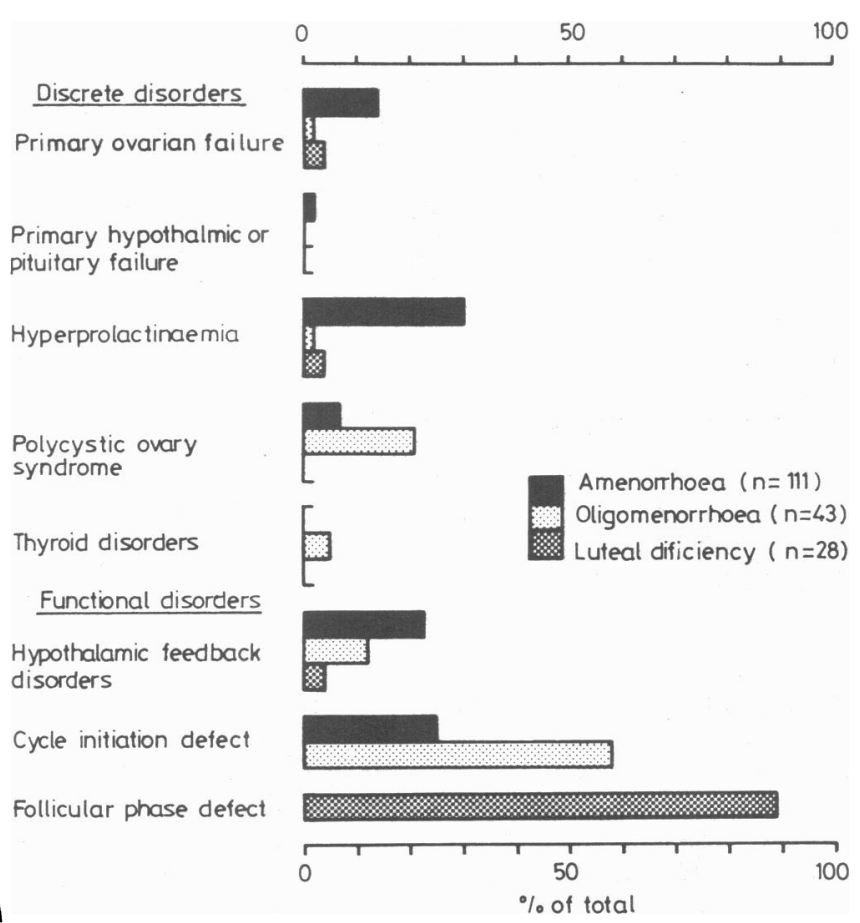

FIG 2-Percentage frequency distribution of disorders classified endocrinologically ${ }^{1}$ accounting for ovulatory failure as primary cause of infertility in patients with amenorrhoea, oligomenorrhoea, or luteal deficiency. Functional disorders were defined by exclusion of all the foregoing discrete disorders. Patients with weight-loss-related amenorrhoea susceptible to dietary treatment were included in the group with hypothalamic feedback disorder. Cycle initiation defect (in oligomenorrhoea or amenorrhoea) or follicular phase defect (in normally menstruating patients with luteal deficiency) implied ovulatory response to clomiphene.

TABLE I-Age and duration of infertility (or duration of amenorrhoea* in that particular group) in the groups of patients studied who received treatment for ovulatory failure or remained untreated with ovulatory infertility

\begin{tabular}{lcccc}
\hline & & & Luteal & Ovulatory \\
& Amenorrhoea & Oligomenorrhoea & deficiency & infertility \\
\hline No of patients & 95 & 42 & 27 & 62 \\
Mean ( I SD) age (and & $27.9 \pm 4.32$ & $26.8 \pm 3.95$ & $29.4 \pm 4.58$ & $28.4 \pm 3.53$ \\
range) (years) & $(19-42)$ & $(20-36)$ & $(20-41)$ & $(20-38)$ \\
Median duration of & $\left.24^{*}\right)$ & 18 & 24 & 24 \\
infertility (and range) & $\left(6-300^{*}\right)$ & $(12-96)$ & $(12-84)$ & $(12-108)$ \\
(months) & & & & \\
\hline
\end{tabular}

cluding four described previously ${ }^{2}$; a fifth was terminated at the patient's request because of triplet pregnancy after gonadotrophin treatment (she has since delivered twins); and the sixth was terminated because of an anencephalic fetus in an ovulatory patient who received no treatment. Excluding terminated pregnancies, the abortion rate was $15 \%(25 / 172)$ and two pregnancies were ectopic $(1 \%)$.

Time-specific cumulative conception rates calculated as for lifetable analysis are shown for each of the groups of patients compared with normal in fig 4. A negative postcoital test result was found after treatment of amenorrhoea in only two patients and of oligomenorrhoea

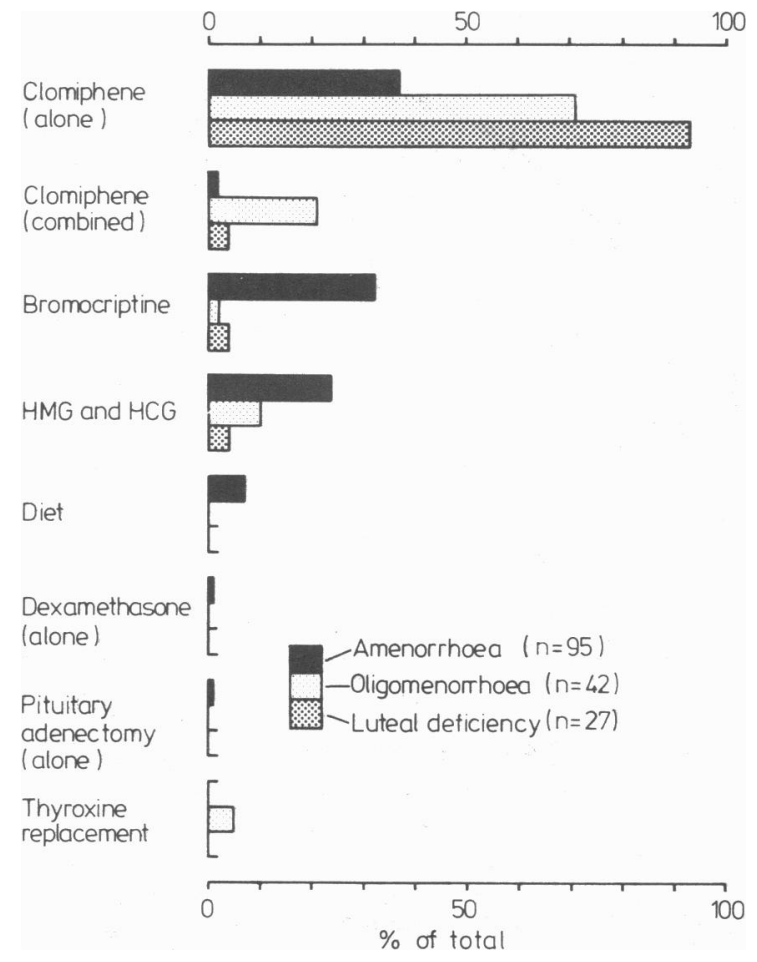

FIG 3-Percentage frequency distribution of treatments applied to induce ovulation in patients with amenorrhoea, oligomenorrhoea, or luteal deficiency. HMG = Human menopausal gonadotrophin. $\mathrm{HCG}=$ Human chorionic gonadotrophin.

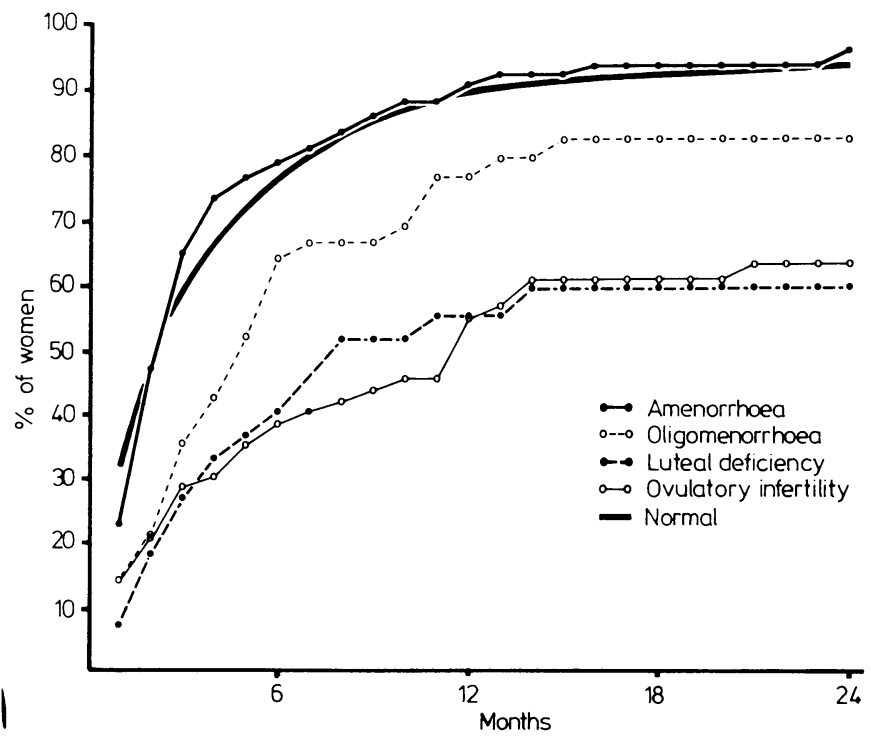

FIG 4-Cumulative conception rates. Results of ovulation induction treatment in anovulatory infertility and without treatment in ovulatory infertility compared with normal ${ }^{112}$ calculated as for life-table analysis, including patients with a negative response to a postcoiral test. 
in two. These made little difference to the results and have therefore been included. A negative postcoital test result was found in eight patients with treated luteal deficiency and in 17 with ovulatory infertility, however, making large differences to the results in these two groups, as shown in fig 5 . For comparison with the results shown for the same patients in fig 5 the actual conception rates in those who continued to particular-end-points in the study are given in table II. The delivery rates are shown in fig 6 and given in table III for the same patients as in fig $\mathbf{5}$ and table II.

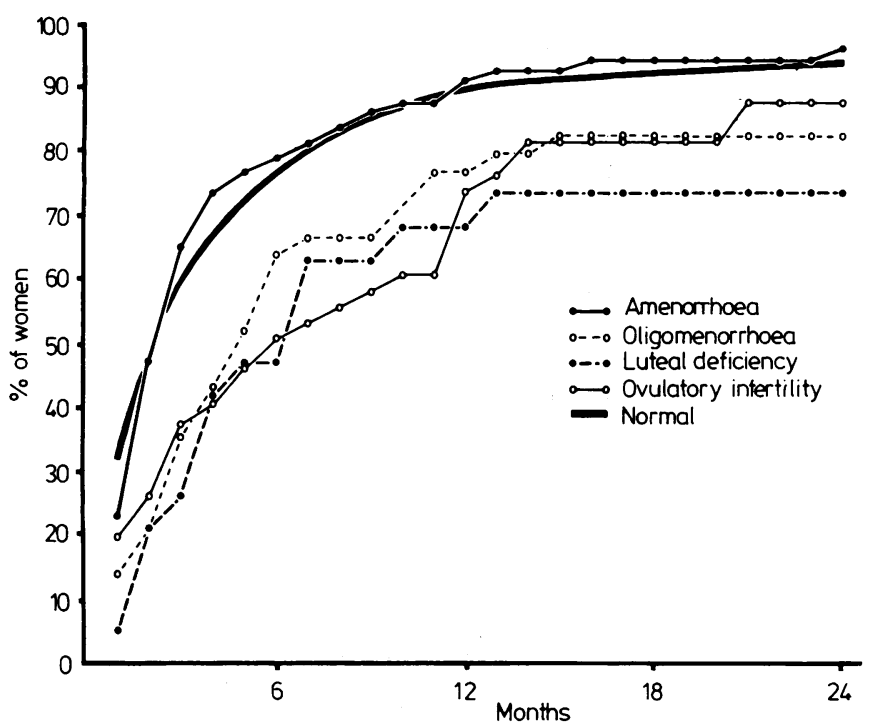

FIG 5-Results as in fig 4 after excluding patients with a negative response to a postcoital test.

TABLE II-Time-specific cumulative conception rates in patients who continued to particular end-points after start of treatment or from first investigation in those with untreated ovulatory infertility, after excluding those with a negative response on postcoital test

\begin{tabular}{ccccc}
\hline End-point & Amenorrhoea & Oligomenorrhoea & $\begin{array}{c}\text { Luteal } \\
\text { deficiency }\end{array}$ & $\begin{array}{c}\text { Ovulatory } \\
\text { infertility }\end{array}$ \\
\hline 6 months & $75 / 95(79 \%)$ & $27 / 42(64 \%)$ & $9 / 19(47 \%)$ & $23 / 45(51 \%)$ \\
12 months & $85 / 92(92 \%)$ & $32 / 41(78 \%)$ & $13 / 19(68 \%)$ & $32 / 42(76 \%)$ \\
18 months & $87 / 91(96 \%)$ & $34 / 39(87 \%)$ & $14 / 17(82 \%)$ & $3541(85 \%)$ \\
24 months & $88 / 90(98 \%)$ & $34 / 37(92 \%)$ & $14 / 17(82 \%)$ & $36 / 38(95 \%)$ \\
\hline
\end{tabular}

TABLE III-Cumulative delivery rates in patients who continued to particular end-points after the start of treatment or from first investigation in those with untreated ovulatory infertility, after excluding patients with a negative response on postcoital test

\begin{tabular}{lcccc}
\hline End-point & Amenorrhoea & Oligomenorrhoea & $\begin{array}{c}\text { Luteal } \\
\text { deficiency }\end{array}$ & $\begin{array}{c}\text { Ovulatory } \\
\text { infertility }\end{array}$ \\
\hline 12 months & $55 / 95(58 \%)$ & $16 / 42(38 \%)$ & $7 / 19(37 \%)$ & $17 / 45(38 \%)$ \\
18 months & $68 / 87(78 \%)$ & $28 / 41(68 \%)$ & $11 / 18(61 \%)$ & $24 / 43(56 \%)$ \\
24 months & $76 / 83(92 \%)$ & $32 / 40(80 \%)$ & $1316(81 \%)$ & $31 / 41(76 \%)$ \\
30 months & $76 / 82(93 \%)$ & $32 / 37(86 \%)$ & $13 / 16(81 \%)$ & $33 / 35(94 \%)$ \\
\hline
\end{tabular}

\section{Discussion}

Our findings show that a simple scheme of investigation and selection of treatment, which can be pursued without alteration in nearly $90 \%$ of cases, can be used very successfully to overcome infertility due to ovulatory failure. To determine the specific efficacy of treatment we first excluded primary ovarian failure, which is untreatable, ${ }^{16}$ and other well-defined absolute causes of infertility. We also excluded patients with rigorously tested failure of postcoital sperm survival, which is a common and well-defined if not absolute cause of infertility in normally menstruating women. ${ }^{15}$ We did not exclude abnormalities such as minor endometriosis or moderate oligospermia, which are widely regarded as causes of infertility, since their contribution is ill-defined and we should like to emphasise that in practice they are better ignored. At two years from the start of treatment the cumulative conception rate calculated as for lifetable analysis was $96 \%$ for treated patients who had amenorrhoea, $83 \%$ for those with oligomenorrhoea, $74 \%$ for those with luteal deficiency, and $88 \%$ for those with untreated ovulatory infertility (fig 5 ). The delivery rates at two-and-a-half years were, respectively, $88 \%, 78 \%, 75 \%$, and $80 \%$ (fig 6). The actual conception and delivery rates were considerably higher in some groups of women who continued to the end of the study periods (tables II and III) but are misleading, being due in these cases to a fall in the number of patients continuing rather than an increase in those conceiving. This illustrates the value of life-table analysis for fertility studies. ${ }^{17}$

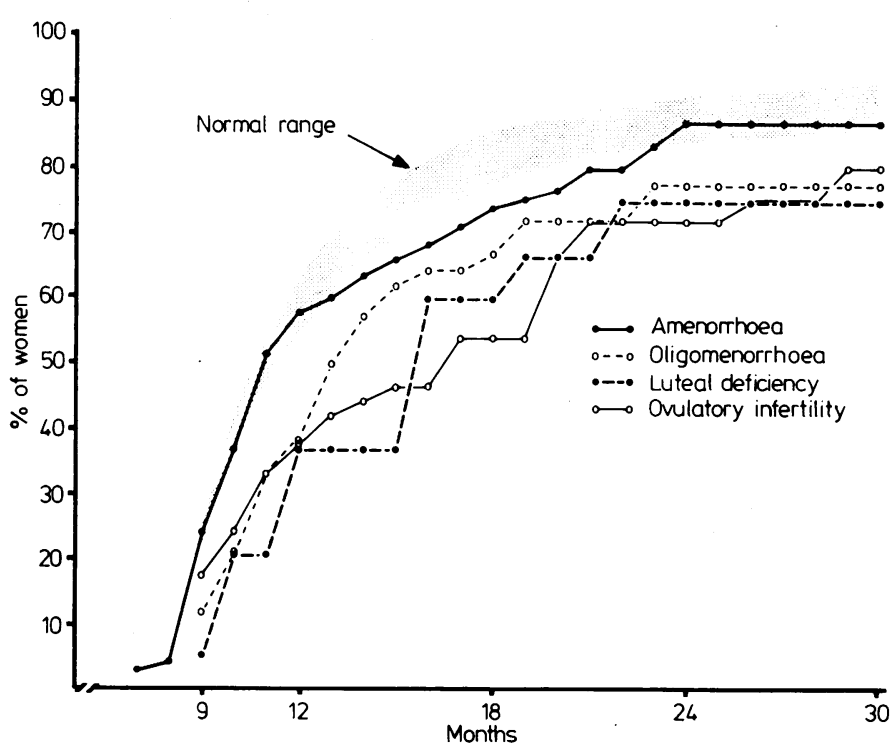

FIG 6-Delivery rates in the same patients as in fig 5 . The normal rates are shown as a range, the limits having been given separately for parous (the higher limit) and nulligravid women (data modified with permission from Vessey et $a l^{13}$ ).

Our results generally represent a sharp improvement in those previously reported in similarly defined groups of patients, ${ }^{18-22}$ discussed in detail elsewhere. ${ }^{1}$ Only the data from Katayama et $a l^{22}$ can be properly compared, however, since they are the only workers to take account of time. Life-table analysis shows that they achieved conception rates at two years of $58 \%$ in luteal deficiency and only $46 \%$ in oligomenorrhoea and amenorrhoea.

If ovulatory failure is the true and only cause of infertility, ovulation induction should theoretically result in a normal conception rate. Unreliable indices of ovulation have clearly undermined the success of treatment in the past, particularly with clomiphene. Although our results show that the conception rate is still not normal in patients with luteal deficiency or oligomenorrhoea (who were mainly treated with clomiphene), it is greatly improved. In amenorrhoea the conception rate is completely normal with clomiphene (and with bromocriptine and gonadotrophins), as we have specifically shown elsewhere. ${ }^{2}$ These results have been achieved without increasing the dose of clomiphene above $100 \mathrm{mg}$ daily and without mid-cycle oestrogen supplementation, which have never been proved to be of any value. That a normal conception rate should be achieved with gonadotrophin treatment in properly selected patients is borne out by reanalysis of Lunenfeld and Insler's original data on oestrogendeficient amenorrhoeic patients ${ }^{20}$ : although only $60 \%$ actually conceived, life-table analysis has revealed a constant monthly chance of conception and a cumulative rate of $91 \%$ after six 
months. ${ }^{23}$ The apparent difference in their two reports was due to an earlier failure to persist with treatment for usually more than a few cycles, understandable in a pioneering era. These findings emphasise the need to continue treatment long enough, given confidence in the diagnostic and therapeutic methods used.

Our results suggest that amenorrhoea represents a pure form of ovulatory failure, being easily and completely overcome. Oligomenorrhoea and luteal deficiency, however, represent more subtle endocrine disorders in which other occult factors may also be partly responsible for infertility, as perhaps in ovulatory infertility. This likelihood is emphasised by further analysis of our data, which shows that advancing age and duration of infertility both, presumably in association, reduced the chance of conception, except in amenorrhoea, in which the chance was equally good however long its duration. The exact contribution to infertility of luteal deficiency, which does not affect all cycles, and the true $\mathrm{effect}$ of its treatment still need to be determined by proper controlled studies.

The results in patients with ovulatory infertility, usually called unexplained infertility, who were given no treatment represent a steady conception rate of about $10 \%$ each month. This is virtually normal apart from the initial higher normal rates, ${ }^{11} 12$ possibly mainly related to coital frequency. ${ }^{24}{ }^{25}$ Coital advice is essential. It is evident that few really have unexplained infertility; in most cases their previous failure has been due simply to adversity of chance. Whether any drug treatment might improve their chance of conception remains to be determined by controlled studies. Our results show that the serum progesterone criterion we used is a reliable index of potential fertility ("ovulation").

We have put our faith in simple and cost-effective methods in the management of anovulatory infertility and believe our results commend them for wider use.

We are grateful to Professor M P Vessey for the detailed data needed to construct the graph for normal delivery rates in fig 6 . We thank the departments of chemical pathology at the Royal Infirmary and Southmead Hospital, Bristol, for hormone assays and the gynaecology clinic and ward staff, without whose enthusiastic help this work could not have been completed. Some of the patients with amenorrhoea were the subject of a previous report. ${ }^{2}$

\section{References}

${ }^{1}$ Hull MGR. Ovulation failure and induction. Clin Obstet Gynaecol 1981; 8:753-85.
2 Hull MGR, Savage PE, Jacobs HS. Investigation and treatment of amenorrhoea resulting in normal fertility. Br Med $\mathcal{f} 1979$;i:1257-61.

3 Hull MGR, Savage PE, Bromham DR, Ismail AAA, Morris AF. The value of a single serum progesterone measurement in mid-luteal phase as criterion of a potentially fertile cycle ("ovulation") derived from treated and untreated conception cycles. Fertil Steril 1982;37:355-60.

4 diZerega GS, Ross GT. Luteal phase dysfunction. Clin Obstet Gynaecol $1981 ; 8: 733-51$.

${ }^{5}$ Hull MGR, Knuth UA, Murray MAF, Jacobs HS. The practical value of the progestogen challenge test, serum oestradiol estimation or clinical examination in assessment of the oestrogen state and response to clomiphene in amenorrhoea. Br $\mathcal{F}$ Obstet Gynaecol 1979;86:799-805.

6 Jacobs HS. Management of prolactin-secreting tumours. In: Studd JWW, ed. Progress in obstetrics and gynaecology. Vol 1. London: Churchill Livingstone, $1981: 263-76$.

7 Britton KE, Quinn V, Brown BL, Ekins RP. A strategy for thyroid function tests. Br Med $\mathcal{F} 1975$;iii:350-2.

${ }^{8}$ Katz M. Polycystic ovaries. Clin Obstet Gynaecol 1981 ;8:715-31.

9 Knuth UA, Hull MGR, Jacobs HS. Amenorrhoea and loss of weight. $\mathrm{Br} \mathcal{F}$ Obstet Gynaecol 1977;84:801-7.

${ }^{10}$ Hull MGR. Dietary restriction and amenorrhoea. $f$ Mat Child Health $1979 ; 4: 104-10$

11 Tietze C. Fertility after discontinuation of intrauterine and oral contraception. Int $\mathcal{F}$ Fertil 1968;13:385-9.

12 Tietze C. Statistical contributions to the study of human fertility. Fertil Steril 1956;7:88-95.

${ }^{13}$ Vessey MP, Wright NH, McPherson K, Wiggins P. Fertility after stopping different methods of contraception. Br Med $\mathcal{F} 1978 ; \mathrm{i}: 265-7$.

14 Hull MGR, Bromham DR, Savage PE, Jackson JAM, Jacobs HS. Normal fertility in women with post-pill amenorrhoea. Lancet 1981 ; i:1329-32.

${ }^{15}$ Hull MGR, Savage PE, Bromham DR. The prognostic value of the postcoital test: a prospective study based on time-specific conception rates. Br F Obstet Gynaecol 1982;89:299-305.

16 O'Herlihy C, Pepperell RJ, Evans JH. The significance of FSH elevation in young women with disorders of ovulation. $\mathrm{Br}$ Med $\mathcal{F} 1980 ; 281: 1447$ 50 .

17 Cooke ID, Sulaiman RA, Lenton EA, Parsons RJ. Fertility and infertility statistics: their importance and application. Clin Obstet Gynaecol $1981 ; 8: 531-48$.

${ }^{18}$ Evans J, Townsend L. The induction of ovulation. Am $\mathcal{F}$ Obstet Gynecol $1976 ; 125: 321-7$

19 Lenton EA, Weston GA, Cooke ID. Long-term follow-up of the apparently normal couple with a complaint of infertility. Fertil Steril 1977;28:913-9.

${ }^{20}$ Lunenfeld B, Insler V. Diagnosis and treatment of functional infertility. Berlin: Grosse Verlage, 1978.

${ }^{21}$ March CM, Davajan V, Mishell DR. Ovulation induction in amenorrheic women. Obstet Gynecol 1979;53:8-11.

${ }^{22}$ Katayama KP, Ju K-S, May M, Jones GS, Jones HW. Computer analysis of etiology and pregnancy rate in 636 cases of primary infertility. $A m \mathcal{F}$ Obstet Gynecol 1979;135:207-14.

${ }^{23}$ Dor J, Itzkowic DJ, Mashiach S, Lunenfeld B, Serr DM. Cumulative conception rates following gonadotropin therapy. Am $\mathcal{f}$ Obstet Gynecol $1980 ; 136: 102-5$

${ }^{24}$ MacLeod J, Gold RZ. The male factor in fertility and infertility. VI. Semen quality and certain other factors in relation to ease of conception. Fertil Steril 1953;4:10-33.

${ }^{25}$ Barrett JC, Marshall J. The risk of conception on different days of the menstrual cycle. Population Studies 1969;23:455-61.
What is "sports anaemia?"

Sports anaemia is a term used to describe a mild anaemia found in athletes. The two ways in which such an anaemia might occur result from either frequent loss of haemoglobin in the urine (march haemoglobinuria) or from inhibition of erythropoiesis in trained athletes. March haemoglobinuria has long been recognised as a complication of walking and running, especially over long distances. Davidson in $1964^{1}$ showed that it is due to mechanical trauma to the red cells in the plantar vessels leading to intravascular haemolysis and hence to a fall in haptoglobin concentration, haemoglobinaemia, and haemoglobinuria. Haemoglobinuria has also been described after karate exercises for strengthening the hands and in drummers who use their hands; in these cases the red cells are damaged in the palmar vessels. If sufficient haemoglobin is lost in the urine iron-deficiency anaemia may develop, but this appears to be rare. Long-distance runners have lower haemoglobin concentrations than control subjects, and although some authors think that this is due to persistent haemoglobinuria and iron deficiency, ${ }^{2}$ this has not been clearly shown. A recent study by Dressendorfer et $a l^{3}$ of the haematological changes in 12 marathon runners during a 20-day road race showed that by the second day there was a significant reduction in haemoglobin concentration and red cell count in all subjects and by day 20 the levels had decreased about $15 \%$ from the initial values and were below the control normal range. Haematuria and haemoglobinuria, however, were rare and were not thought to be a major factor in causing anaemia, especially since there was a significant rise in plasma iron concentrations. This suggested that the mechanism of the anaemia was a reduction of erythropoiesis, although no direct evidence for this was obtained. The authors found no impairment in the athletes' performance and considered that the anaemia was a physiological "pseudoanaemia" induced by exercise that requires no treatment. There is no treatment as such for march haemoglobinuria, but it may be minimised by wearing shoes with resilient soles and avoiding running on hard surfaces.-DIANA SAMSON, consultant haematologist, London.

${ }^{1}$ Davidson RJL. Exertional haemoglobinuria: a report on three cases with studies on the haemolytic mechanism. F Clin Pathol 1964;17:536-40.

Hunding A, Jordan R, Pauler P-E. Runner's anaemia and iron deficiency. Acto Med Scand 1981;209:315-8.

Dressendorfer RH, Wade CE, Amsterdam EA. Development of pseudoanaemia in marathon runners during a 20 -day road race. $\mathcal{F} A M A$ 1981;246:1215-9. 